\title{
SHRINKAGE OF HEAT STORAGE MATERIAL OBTAINED BY MIXING COMMERCIAL LIQUID AND SOLID PARAFFINS
}

\author{
${ }^{1}$ Aimbetova I.O., ${ }^{2}$ Suleimenov U.S., ${ }^{2}$ Ristavletov R.A., ${ }^{2}$ Kalshabekova E.N., \\ ${ }^{2}$ Saparov S.A., ${ }^{2}$ Kudabayev R.B., ${ }^{2}$ Bekbatyrkyzy L. \\ ${ }^{1}$ Khoja Akhmet Yassawi International Kazakh-Turkish University, Kazakhstan, e-mail: science@ayu.edu.kz; \\ ${ }^{2}$ M. Auezov South Kazakhstan state University, Kazakhstan,e-mail:rar_1967@mail.ru \\ The paper studies the heat storage materials (HSM) shrinkage curve from the temperature obtained by mix- \\ ing liquid and solid paraffins, which is markedly different from the heat release curve. It is shown that the sum of \\ enthalpy of melting and phase transition in the crystalline state thermal storage materials based on paraffin depends \\ on: the width of the fractional composition HSM and purity in content of $\mathrm{n}$ - alkanes; the fractional part HSM; from \\ the content of the number of even and odd $n$ - alkanes and their relationships. The shrinkage of the developed HSM \\ during crystallization and expansion during melting, depending on the temperature, is studied. The dependence of \\ shrinkage HSM on temperature is obtained and their shrinkage coefficients on temperature are analyzed. It was \\ found that HSM-25-3 has several shrinkage peaks and two heat release peaks during crystallization and phase transi- \\ tion. This is a feature of the chemical compound of commercial paraffin, which is related to the group of complex \\ hydrocarbons and n-alkanes. The study of shrinkage of the developed heat storage materials allowed us to study \\ the dependence of the shrinkage coefficient on temperature. The dependence of the shrinkage coefficient of the heat \\ storage material HSM-25-1, obtained by mixing n-alkanes mainly $\mathrm{C}_{17} \mathrm{H}_{36}$ and $\mathrm{C}_{18} \mathrm{H}_{38}$, on temperature is similar to \\ the shrinkage dependence when a mixture of odd $\left(\mathrm{C}_{17} \mathrm{H}_{36}\right)$ and even $\left(\mathrm{C}_{20} \mathrm{H}_{42}\right)$ n-alkanes has two shrinkage peaks, and \\ the resulting HSM-25-1 has four shrinkage peaks. The total shrinkage during crystallization and phase transition is \\ $9.56 \%$ of the volume.
}

Keywords: heat storage materials, solid paraffins, n-alkanes, phase transition, crystallization

The demand for clean energy all around the world is constantly growing due to the rapid growth of the economy and the standard of living. The construction industry, which is the main consumer of material and energy resources, has a great prospect for the development of innovative energy-saving and thermally efficient building materials [1-3]. Over the past decades, a lot of literature has appeared on materials with phase change and hidden methods of storing heat used in construction. Accordingly, it is important to analyze the data of recent years in order to learn more about the application of materials with a phase change in construction. An overview of the application of materials with phase change in construction is considered in several aspects, such as basic materials for phase change in buildings, applications of materials with phase change, thermal properties of the phase transition of materials and the effects of using such materials. Materials with phase change as thermal energy storage systems are potential because of their thermal mass and thermal comfort. These materials for hidden heat storage have an extremely high energy storage density than conventional materials. Recently, in the whole world, in the building fencing industry, microencapsulation technologies of finely dispersed heat-accumulating materials in composites have been leading to create a large surface area for improving heat transfer $[4,5]$. Heat supply systems in residential and public buildings differ in the periodic nature of the heat source. At the same time, the air temperature in the premises can fluctuate within $3.5^{\circ} \mathrm{C}$ due to the ther- mal inertia of the building envelope structures. However, the maximum energy consumption is in the daytime, when a comfortable temperature is set $\left(20-22^{\circ} \mathrm{C}\right)$. In this case, there is a need to obtain heat storage materials (HSM) with a melting point close to $25^{\circ} \mathrm{C}$, for use in the enclosing structures of buildings to regulate heat in their premises [6].

Therefore, a very urgent task is to develop heat storage materials based on commodity paraffins for enclosing structures of buildings with specified thermal properties.

Currently, installations for heat storage are widely used in various branches of science and technology and in everyday life. They are used in heat power engineering, construction for efficient use of thermal energy and heat storage from solar radiation, to reduce energy consumption.

Thermal storage plants use natural inorganic and organic materials that accumulate heat. Inorganic materials include salts and their solutions, crystallohydrates, various metals, and organic materials include solid paraffins, ceresines and n-alkanes [7-9].

Much attention is paid to the operation of heat-accumulating material in heat accumulators due to the property of shrinkage.

Commodity paraffins in the crystallized state are a solid mass and when they are filled with heat accumulators, various heat storage devices with subsequent melting of paraffin, its volume increases. Different expansion of the heat storage material may cause an increase in pressure in the sealed heat accumulator. It is known that the pressure increase in the heat 
accumulator with heat-accumulating materials based on commercial paraffins can reach $10 \ldots 50 \mathrm{MPa}[8,9]$. But it should also be noted that an increase in the pressure in the heat storage device or apparatus causes an increase in the melting temperature THERE by several degrees [10-12]. In this regard, when choosing a heat storage material for heat accumulators and evaluating the pressure that develops during filling in the solid state and subsequent melting of the material, it is necessary to evaluate the shrinkage and expansion of the heat storage material during operation.

Purpose of the study - develop and investigate the thermophysical properties of heat accumulating materials based on commercial paraffins produced in the industry for building envelope structures.

\section{Material and methods of research}

The melting and freezing characteristics of phase transitions of heat-collecting materials include the changes that these materials exhibit during heating and cooling, for example: melting and freezing ranges, melting congruence, nucleation characteristics, melt cooling, and resistance to thermal Cycling [7]. Thus, in order to ensure the long-term operation of the hidden heat storage, it is necessary to thoroughly know the nature of melting and freezing of substances that generate melting heat, in particular, their defrosting as a result of repeated melting and freezing of these substances. The methodology of scientific research is based on the development of methods for obtaining heat storage materials based on commercial paraffins by mixing components, in obtaining HSM with specified thermal characteristics, studying the component composition, physical, chemical and thermal properties of their properties, in the study of their operational properties. The developed heat storage material based on commercial paraffins is obtained by mixing the initial liquid and solid paraffins in different mass fractions. Determination of the mass fraction of mixing of the initial liquid and solid paraffins was performed in accordance with the recommendations of [13]. Mixing of commercial liquid and solid paraffins and their fractions was performed at a temperature of $40-50^{\circ} \mathrm{C}$ and thorough mixing of the composition with a mixer in laboratory conditions. The exact fractional composition of solid paraffins was determined by gas chromatographic analysis on the gas chromatography-mass spectrometer GGMS-QP 2010Ultra, and liquid paraffins on the liquid chromatograph LC-20P (Japan) on the basis of the Testing regional laboratory of engineering profile "Structural and biochemical materials" of the Auezov University.

\section{Research results and discussion}

Phase-transitive heat-storage materials (HSM) based on commercial paraffins and other hydrocarbons have the ability to multipass from one phase to another through several cycles of melting and crystallization, while maintaining their original characteristics while remaining inert to any materials. In this regard, these materials are successfully used in the construction industry as heat-accumulating materials with a melting point above $50^{\circ} \mathrm{C}$.

Paraffins and n-alkanes in the liquid state are low-viscosity transparent liquids with a relative density in the range of $750-800 \mathrm{~kg} /$ $\mathrm{m} 3$. Due to shrinkage, paraffins and n-alkanes in the crystalline state are solid substances with a density of 860-900 kg / m3 [14-16].

According to the method, the developed heat-accumulating material based on commodity paraffins will be obtained by mixing the initial liquid and solid paraffins in different mass fractions. Determination of the mass fraction of mixing of the initial liquid and solid paraffins was performed in accordance with the results of the research [17]. According to the results of [18], it is recommended to mix n-alkanes of the neighboring series, since in this case the difference in their melting temperatures will be the smallest. For example, by mixing individual n-alkanes $\mathrm{C}_{19} \mathrm{H}_{40}$ with a melting point of $32^{\circ} \mathrm{C}$ and n-alkane $\mathrm{C}_{20} \mathrm{H}_{42}$ with a melting point of $36.7^{\circ} \mathrm{C}$ in a ratio of $33.1: 66.9$, a heat-accumulating material with a melting point of $35^{\circ} \mathrm{C}$ can be obtained [6].

Figure 1 shows the shrinkage curves of HSM-25-3 obtained by mixing commercial liquid and solid paraffins.

The graph in figure 1 shows that there are four main shrinkage peaks in HSM-25-3 compared to the graphs of the shrinkage dependence on the temperature of individual $n-$ alkanes in accordance. This is due to the fact that at $25^{\circ} \mathrm{C}$, when this heat storage material is cooled, a number of hydrocarbons simultaneously crystallize. It should be noted that the total value of the thermal effect of HSM-25-3 is noticeably lower than that of a mixture of individual n-alkanes with the same melting point.

This is due to the complexity of the chemical composition of commercial paraffin, which contains along with n-alkanes hydrocarbons of other groups [7], it is believed that these hydrocarbons have a significantly lower melting point compared to individual n-alkanes. In addition, some of these hydrocarbons may 
not crystallize during cooling, forming a solid crystalline mass. For these HSM-25-3, the shrinkage during crystallization was $9.02 \%$ of the volume, during the phase transition to the crystalline state $-0.77 \%$ of the volume, and the total shrinkage was $9.79 \%$ of the volume.

Hence, it can be concluded that the width of the fractional composition of heat storage material significantly affects the shrinkage of HSM-25-3: it does not change for the phase transition, and it decreases slightly during melting.

Comparison of data on shrinkage of developed heat storage materials obtained by mixing n-alkanes HSM-25-1 and HSM-25-2 and mixing liquid and solid paraffins HSM-25-3 shows that HSM-25-1 and HSM-25-2 have higher shrinkage values than HSM-25-3.

Hence, it can be concluded that the width of the fractional composition of the heat storage material does not affect the shrinkage during the phase transition and has little effect on their shrinkage during melting.

The results of the shrinkage study of the developed heat storage materials are shown in table.
To assess the relationship between heat release during crystallization and phase transition and shrinkage, figures 2, 3 and 4 show their temperature dependences for HSM-25-1, HSM-25-2 obtained by mixing individual nalkanes and HSM-25-3 obtained by mixing liquid and solid paraffin.

Comparison of graphs of the dependence of the heat capacity and the shrinkage curve on the temperature of HSM-25-1 and HSM-25-2 obtained by mixing individual nalkanes (fig. 2 and 3 ) shows that the shrinkage curve is similar to the heat release curve.

The shrinkage curve of HSM-25-3 obtained by mixing liquid and solid paraffins differs markedly from the heat release curve (Fig. 4). In the graphs of the figure, you can see that HSM-25-3 has several shrinkage peaks and two heat release peaks during crystallization and phase transition, i.e. it should be noted that the shrinkage coefficient curves and the heat release graphs do not coincide. This is due to the complexity of the chemical composition of commercial paraffin, which contains along with n-alkanes, hydrocarbons of other groups [7].

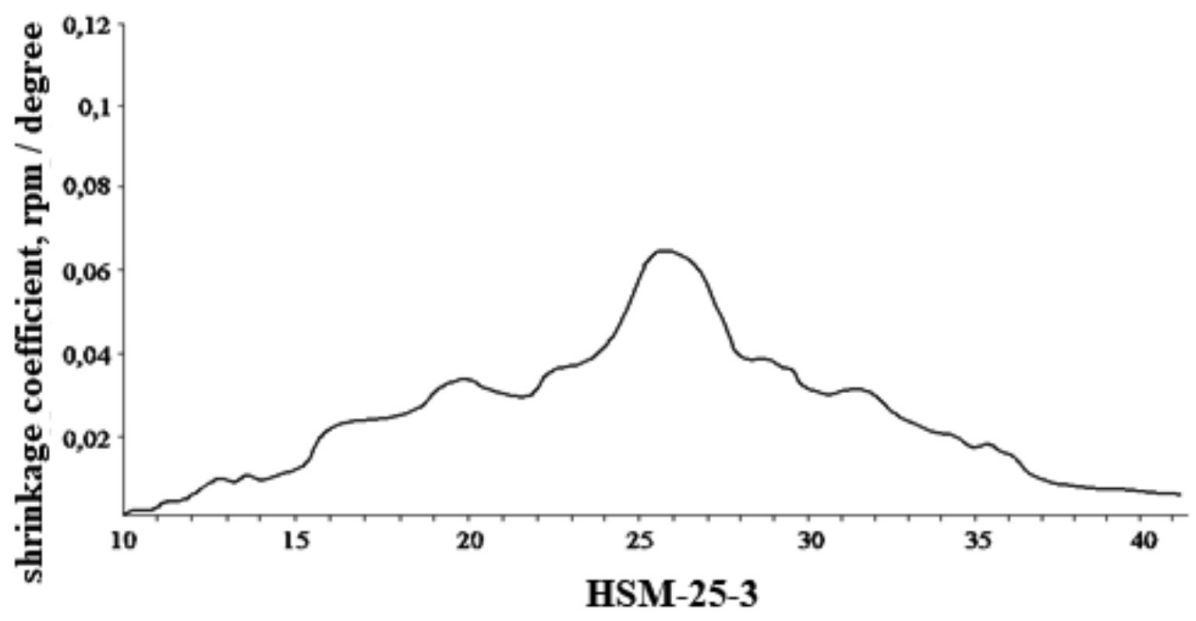

Fig. 1. Graph of the dependence of the shrinkage coefficient HSM-25-3 obtained by mixing commercial liquid and solid paraffin from the temperature

Shrinkage values of heat storage materials HSM-25-1, HSM-25-2 and HSM-25-3 [6]

\begin{tabular}{|c|c|c|c|c|}
\hline HSM & \multirow{2}{*}{$\begin{array}{c}\text { Melting } \\
\text { point, }\end{array}{ }^{\circ} \mathrm{C}$} & at phase transitions & during crystallization & $\begin{array}{c}\text { amount of shrinkage during } \\
\text { melting and phase transition }\end{array}$ \\
\cline { 3 - 5 } & & 1,39 & 8,17 & 9,56 \\
\hline HSM-25-1 & 25 & 1,41 & 8,6 & 10,01 \\
\hline HSM-25-2 & 25 & 0,77 & 9,02 & 9,79 \\
\hline HSM-25-3 & 25 & \multicolumn{2}{|c|}{} & \\
\hline
\end{tabular}




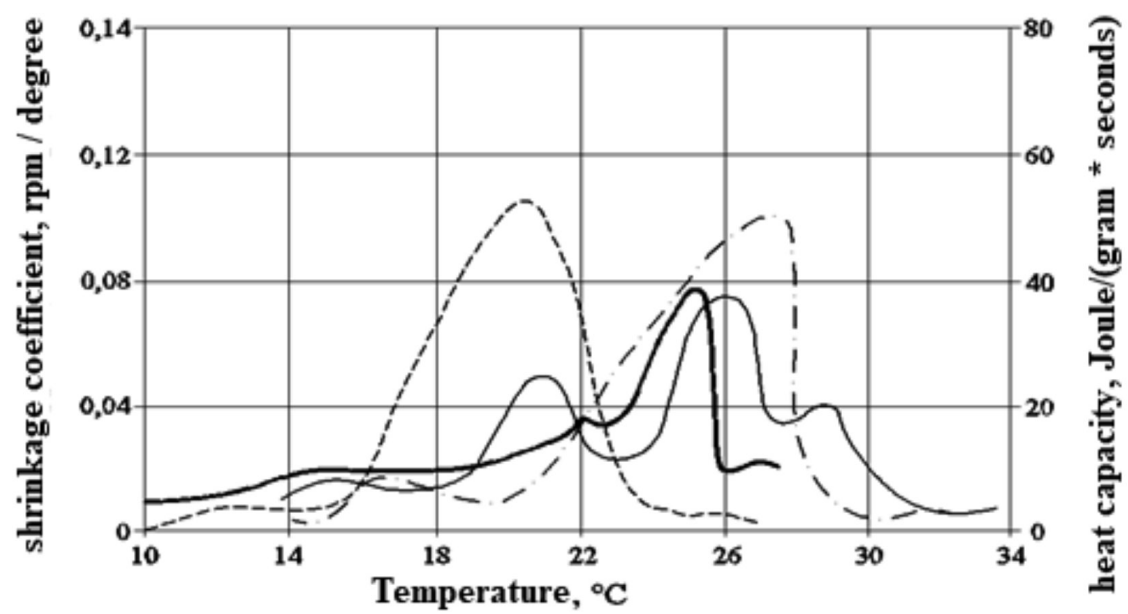

Fig. 2. Graphs of the dependence of the shrinkage coefficient and heat capacity HSM-25-1 on the temperature

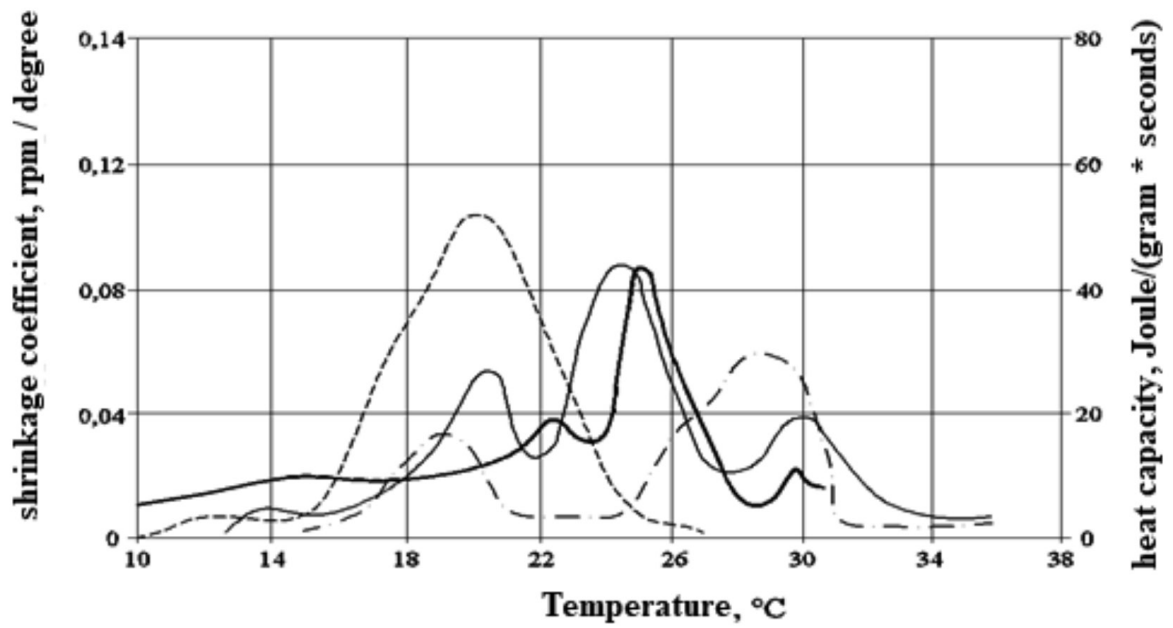

Fig. 3. Graphs of the dependence of the shrinkage coefficient and heat capacity HSM-25-2 on the temperature

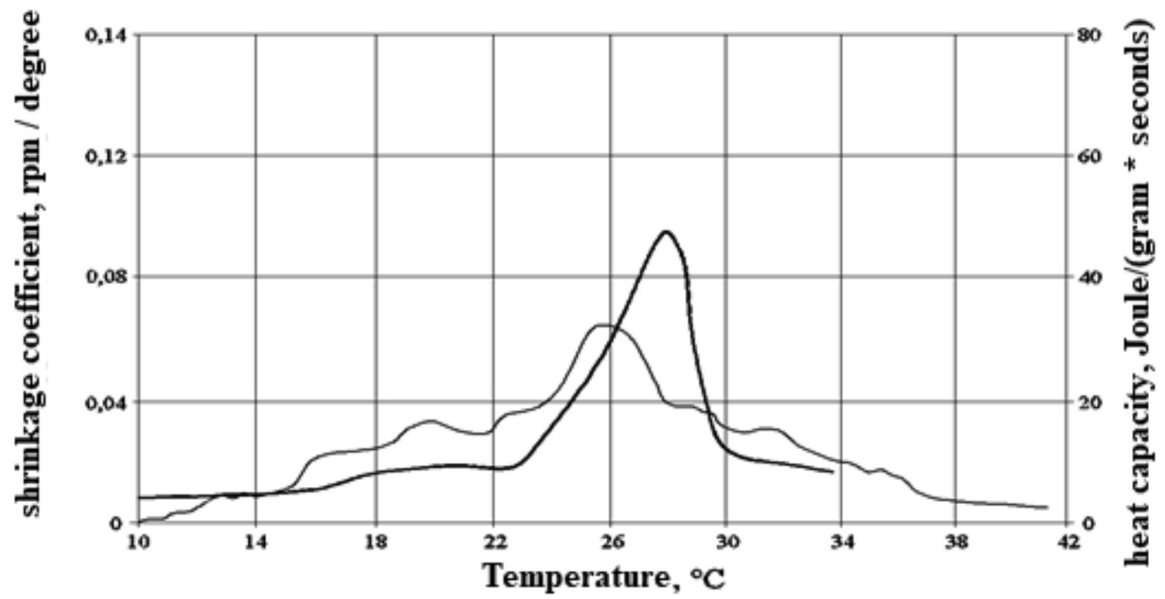

Fig. 4. Graphs of the dependence of the shrinkage coefficient and heat capacity HSM-25-3 on temperature 


\section{Conclusion}

The shrinkage dependences on the temperature of individual n-alkanes in HSM25-3 obtained by mixing liquid and solid paraffins have three (four) shrinkage peaks. This is explained by the fact that at $25^{\circ} \mathrm{C}$ and when this heat storage material is cooled, a number of hydrocarbons simultaneously crystallize. it should be noted that some results are similar to other studies by other authors [7], for example, the identity of the values of the released thermal effect of HSM-25-3 is significantly lower than that of other mixtures of individual $\mathrm{N}$-alkanes, while the melting point is identical. this is an indication of the values of the most heat-accumulating materials by features in microkilograms of the same melting point, which is explained by the complexity of the chemical compound of commercial paraffin containing hydrocarbons of other groups along with n-alkanes.

For HSM-25-3, the shrinkage during crystallization was $9.02 \%$ of the volume, during the phase transition to the crystalline state $0.77 \%$ of the volume, and the total shrinkage was $9.79 \%$.

The work was carried out within the framework of the grant project AR05030618, funded by the Ministry of education and science of the Republic of Kazakhstan.

\section{References}

1. Cheng Fei, Wen Ruilong, Huang Zhaohui. Preparation and analysis of lightweight wall material with expanded graphite (EG)/paraffin composites for solar energy storage // Applied Thermal Engineering, 2017. 120. 107-114.

2. Cui Yaping, Xie Jingchao, Liu Jiaping. A review on phase change material application in building // Advances In Mechanical Engineering, 2017.9 (6). 28.

3. Wahid Mazlan Abdul, Hosseini Seyed Ehsan, Hussen Hasanen M. An overview of phase change materials for construction architecture thermal management in hot and dry climate region // Applied Thermal Engineering, 2017. 112. 1240-1259.

4. Alexeev V. A., Shishanov A.V., Chukin V. F., etc. Heat storages based on shape-stable phase-transitional material // Applied Thermal Engineering. 2014. 28(4). 261-265.

5. Serrano Susana, Barreneche Camila. Fernandez A. Ines Composite gypsum containing fatty-ester PCM to be used as constructive system: Thermophysical characterization of two shape-stabilized formulations // Energy And Buildings, 2015 86. 190-193.

6. Suleimenov U.S., Aimbetova I.O., Ristavletov R.A., Kudabaev R.B. Obtaining heat-accumulating materials by displacement of individual n-alkanes and their thermophysica properties / SCIENTIFIC ASPECT. 2019. 3.112 p. URL: https:// www.elibrary.ru/item.asp?id=41388554

7. Kalinichenko A.Yu. Development and research of heat storage materials based on liquid paraffins // Stavropol: Sevkavstu, 2004. 136. URL: http://tekhnosfera.com/razrabotkai-issledovanie-teploakkumuliruyuschih-materialov-na-osnovezhidkih-parafinov.

8. Pereverzev A.N., Kalinichenko A.Yu., Batasheva A.A. Application of n-alkanes as a TAM as an environmentally safe material // Materials of the VII regional scientific and technical conference "University science - North Caucasus region". Natural and exact Sciences, technical and applied Sciences. Stavropol: Sevkavstu, 2003. 1. 110-112.

9. Snezhkin Yu.F., Mikhailik V.A., Korinchevskaya T.V. Specific heat capacity and thermal conductivity of heat storage materials based on paraffin, brown coal and polyethylene waxes // Problemele Energeticii Regionale. Termoenergetice, 2014. 2(25). 38-46.

10. Sari Ahmet. Thermal Energy Storage Properties and Laboratory-Scale Thermoregulation Performance of Bentonite/ Paraffin Composite Phase Change Material for Energy-Efficient Buildings // Journal Of Materials In Civil Engineering, 2017. 29 (6). Article Number: 04017001

11. Dupin A.V., Korepanov E.V. Modeling of the thermal regime of a room taking into account the use of heat-accumulating materials // Vestnik MGSU, 2011. 7. 137-142.

12. Vashouri E.R., Aliev R.V. Martynova G.S., Azizov A.G. Heat storage materials based on polyolefins and low molecular weight waxes // Plastic. 2012. 10. 42-47.

13. Suleymenov U.S. Thermal insulation and acoustic materials. Textbook. Shymkent, SKSU, 2014. 96.

14. Aimbetova I.O., Suleymenov U.S., Kambarov M.A., Kalshbekova E., Ristavletov R.A. Thermophysical properties of phase transparent heat-material materials used in construction// Advances in curr ent natura 1 sciences. 2018. 12. 9-13.

15. Abhat A. Low temperature latent heat thermal energy storage: heat storage materials / / Solar Energy. 1981. 30(4). 313-332.

16. Kipriyanova E.H., Fadeeva T.F., Grishin A.P. on the chemical composition, structural-mechanical and dilatometric properties of petroleum paraffins and ceresins // Izvestiya VUZ'OV. Oil and gas, 1989, 12. 45-47.

17. Alexandrova E.A., Grishin A.P., Lobachev Yu.Y. Investigation of contractional stresses in dispersed structures of paraffin-containing systems // University News. Oil and gas, 1975. 10. 57.

18. Pereverzev A.N., Kalinichenko A. Yu., Ovcharov S.N. Investigation of shrinkage of heat storage materials obtained by mixing individual n-alkanes and fractions of liquid paraffins // News of higher educational institutions. North Caucasus region. Technical science. Novocherkassk, 2004. 2. 129-130.

19. Aimbetova I.O., Suleimenov U., Ristavletov R.A. Study of shrinkage of heat storage materials for building envelope structures // Materials of the II International Scientific Conference "MIP: Engineering-2020 - Modernization, Innovations, Progress: Advanced Technologies in Material Science, Mechanical and Automation Engineering". Krasnoyarsk, Russia, 2020. 5. 51-57.

20. Aimbetova I.O., Suleymenov U.S., Kostikov O.A., Imanaliev K.E., Ristavletov R.A., Kambarov M.A. Energoactive multilayered construction of fencing with a thermal-accumulating layer // Bulletin of the national Academy of Sciences. Almaty, 2018. 4. 57-62. 